\title{
Sialolithiasis in a 19 year old male: A case report
}

\author{
Richa Wadhawan ${ }^{1 *}$, Vinay Mohan ${ }^{2}$, Sonal Gupta ${ }^{3}$, Himani Lau ${ }^{4}$ \\ ${ }^{1}$ Reader, ${ }^{2-4}$ Professor, ${ }^{1,2}$ Dept. of Oral Medicine, Diagnosis \& Radiology, ${ }^{3}$ Dept. of Pedodontics \& Preventive Dentistry, ${ }^{4}$ Dept. of \\ Conservative Dentistry \& Endodontics, ${ }^{1,4}$ Institute of Dental Education \& Advance Studies, Gwalior, Madhya Pradesh, ${ }^{2,3}$ K.D. Dental \\ College, Mathura, Uttar Pradesh, India
}

*Corresponding Author: Richa Wadhawan

Email: richawadhawan@gmail.com

\begin{abstract}
Sialolithiasis is a condition characterized by the obstruction of a salivary gland or its excretory duct due to the formation of calcareous concretions, resulting in salivary ectasia and subsequent dilatation of the salivary gland. This disease is mostly seen in adults or young adults, and seldom develops in children with submandibular gland duct being the most common site. This case report describes a 19 year old patient presenting with pain and swelling in right side of floor of mouth. Sialolithiasis of right submandibular gland was diagnosed based on clinical and radiographic examination. The sialolith was removed under local anesthesia.
\end{abstract}

Keywords: Sialolithiasis, Submandibular gland, Intraductal, Intraglandular, Sialo-MRI, Lithotripsy.

\section{Introduction}

The most frequent benign non neoplastic salivary disorder representing about $50 \%$ of all major salivary gland disorders is sialolithiasis. ${ }^{1}$ Prevalence rate is as low as $1 \%$ of the population with symptomatic sialolithiasis occurring at a rate of $0.45 \% .^{2}$ Submandibular gland or its duct has highest tendency for sialolithiasis and cause chronic infection. It accounts for $80 \%$ of cases followed-by $19 \%$ in the parotid and $1 \%$ in the sublingual glands. Male predilection is $2: 1$ and occurs between $2^{\text {nd }}$ and $6^{\text {th }}$ decade of life. It is rare in children and accounts for $3 \%$ of all sialolithiasis. ${ }^{3}$ Obstruction of salivary secretion by a calculus is the prime characteristic and it is associated with swelling, pain, pus discharge and inflammation in certain cases. Symptoms are usually unilateral in nature and it has a multifactorial etiology. Salivary calculi is formed from the deposition of calcium salts within the ductal system of salivary glands usually originating from desquamated epithelial cells, foreign bodies, microorganisms and/or mucous plugs. Obstruction, xerostomia, dehydration, increase in salivary $\mathrm{pH}$ associated with oropharyngeal sepsis and impaired crystalloid solubility, certain medications such as psychiatric drugs, anti hypertensive drugs and anticholinergic drugs are traditional etiopathogenetic factors. Physiologically, microliths may be detected following precipitation within redundant secretory vesicles which become symptomatic and act as a nidus. ${ }^{4}$

\section{Case Report}

A 19 year old male patient came to the Department of Oral Medicine, Diagnosis and Radiology, Institute of Dental Education and Advance Studies, Gwalior, Madhya Pradesh with chief complaint of pain and swelling in the right back jaw region since 3 months. Pain was dull and intermittent in nature with history of recurrent swelling during meals and subsided on its own after meals. Extra-oral examination was non contributory at the time of examination. Intra-oral examination revealed a large, firm and tender swelling in the right posterior floor of mouth with no associated discharge or bleeding reported from the site. When the gland was palpated, saliva could be seen at the duct orifice and the gland was tender. Occlusal radiographic examination revealed faint solitary small ovoid radioopague fleck on the right side. A cone beam computed tomography scan (CBCT) was taken, which confirmed the presence of calculi \{Fig. 1, 2, 3 (a), 3(b)\}. Based on these findings the patient was diagnosed with a sialolith in the submandibular gland duct. Surgical removal of the sialolith was planned and performed under local anesthesia (Fig. 4). With antibiotic coverage under local anesthesia, incision was placed longitudinally along the margins and was placed at the ductal orifice and calculi was exposed and retrieved. The calculus was removed in total and was followed by a satisfactory healing process. The sialolith was of size $3 \times 3.5$ mm (Fig. 5).

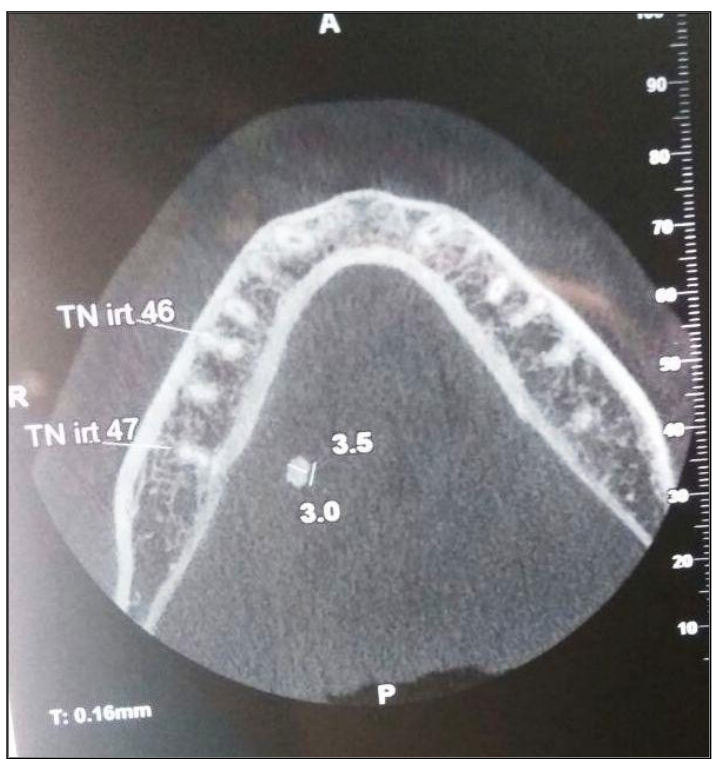

Fig. 1: Axial view of CBCT depicting small ovoid shaped radiopacity in right floor of mouth 


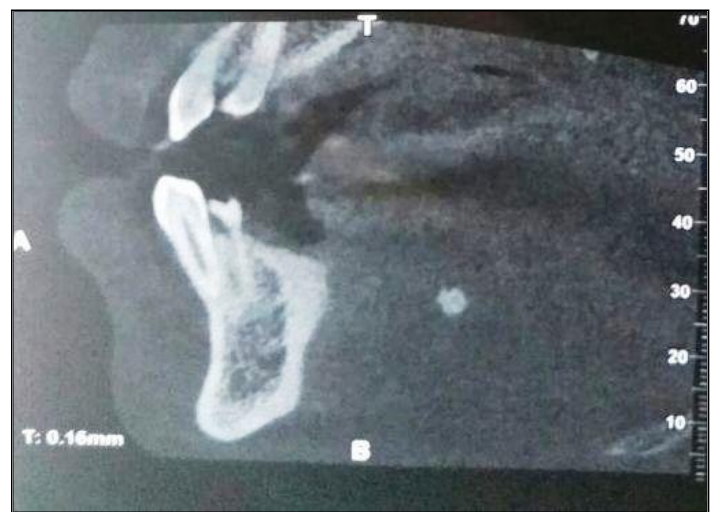

Fig. 2: Sagittal view of CBCT depicting small ovoid shaped radiopacity in right floor of mouth

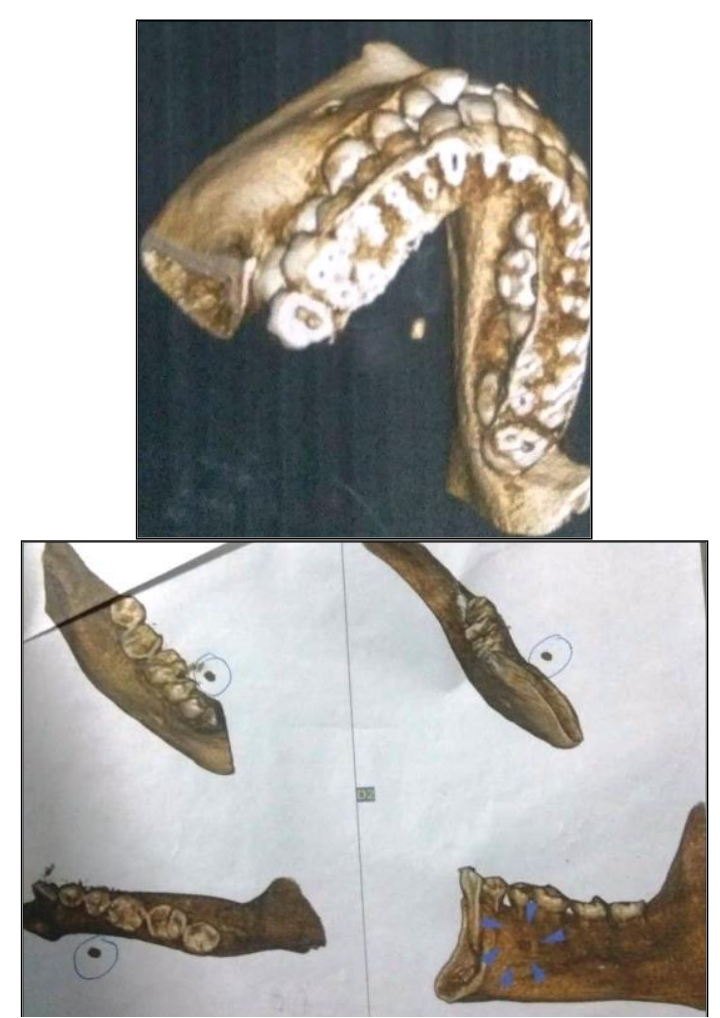

Fig 3 (a), (b) 3D reconstruction

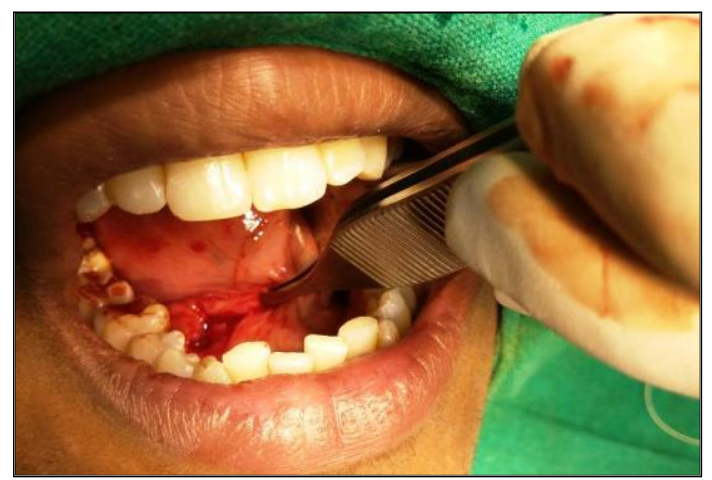

Fig. 4: Surgical procedure

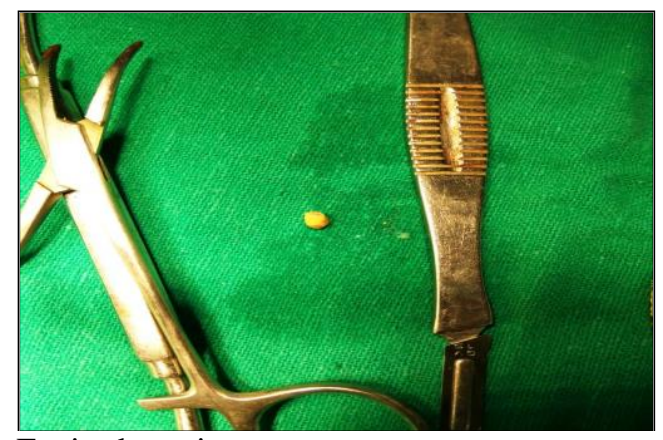

Fig. 5: Excised specimen

\section{Discussion}

Wharton's duct has highest predisposition to sialolithiasis owing to the fact that the excretory duct is tortuous and much longer as compared to other ducts. Also saliva in the submandibular gland flows against gravity, the gland has an alkaline secretion and it contains a higher quantity of mucin proteins, calcium and phosphate. Intraductal calculi are comparatively more common than intra-glandular calculi. When calculus is of smaller size in hilum they are asymptomatic. Symptoms commence when calculi become very large in size and round and elongated in shape. ${ }^{5}$ Understanding of its clinical features by diagnostician leads to easy diagnosis. Radiographs act as essential diagnostic aids. Radiopaque calculi are best seen in occlusal radiographs. For radiolucent calculi sialography is a useful tool in diagnosis. Contraindications for sialography include acute infection or patients allergic to contrast material. ${ }^{6}$ Gold standard in diagnosis is ultrasonography with about 99\% accuracy though its use is limited to operator dependency. ${ }^{7}$ With the invention of newer techniques such as scintiography, computed tomography, digital subtraction sialography and sialoendoscopy the diagnostic aspect of sialolithiasis have revolutionized. ${ }^{8}$ However, computed tomography use has become limited in modern radiology due to radiation exposure. ${ }^{9} \mathrm{X}$-ray sialography remains the standard investigation tool due to its higher spatial resolution..$^{10}$ Magnetic resonance sialography is now being considered as a better alternative due to the non-invasive nature and level of comfort with no risk of radiation exposure. ${ }^{11}$ It is utilized by using special magnetic resonance sequences such as 3D CISS and RARE where $\mathrm{x}$ ray sialography cannot be performed. ${ }^{12}$ The size of calculi in salivary gland varies to a great extent. On the basis of a review of literature, most of the sialoliths are usually of 5 $\mathrm{mm}$ in maximum diameter and all the stones over $10 \mathrm{~mm}$ should be reported as a sialolith of unusual size. ${ }^{13}$ The average size of the salivary calculi lies between 3 and 18 $\mathrm{mm} .{ }^{14}$ According to Lutsmann et al, sialoliths measuring $<10 \mathrm{~mm}$ account for $78.8 \%$ of cases, while those measuring $10-15$ and $>15 \mathrm{~mm}$ account for 13.6 and $7.65 \%$ of cases, respectively. ${ }^{15,16}$ In the present case, the sialolith was 3.5 $\mathrm{mm}$ in size. The management of sialolith is based on its location, size, mobility in ductal system and the symptoms associated with it. Those calculi which are peripherally situated and are small in size can be removed via massage, 
widening of the orifice with a lacrimal probe, moist warm heat application along with administration of sialogogues. It is generally expelled out as a single piece or in fragments. ${ }^{17}$ Most calculi will respond to antibiotics, combined with simple sialolithotomy. Surgical management includes transcervical sialadenectomy. Despite being invasive it is widely used for perihilar and intraglandular obstructive salivary diseases. Demerits of procedure include functional, neurologic, and aesthetic sequelae. ${ }^{18}$ Sialoliths within gland requires submandibular sialoadenectomy or partial parotidectomy. Temporary or permanent injury to marginal branch of facial nerve, scar formation, alteration of sensation and functional incapicitance such as reduction in saliva are few risks associated with this procedure. ${ }^{19}$ Once the sialolith has been located, the orifice of the salivary duct has to be surgically enlarged with a long incision under local anesthesia and expulsion of sialolith will occur by exerting small pressure at the level of the distal ligature through the incision. Risks of this procedure include infection, bleeding, numbness to floor of mouth and duct scarring resulting in recurrent gland swelling. ${ }^{20}$ Conservatively gland-preserving techniques for managing salivary gland obstructions have become possible because of improved radiologic imaging, better optical systems and endoscopic devices and the introduction of minimally invasive therapeutic options. These include extracorporeal shock wave lithotripsy, operative sialoendoscopy, videoassisted transoral and transcervical stone removal, and ductal rehabilitation through interventional radiology and sialoendoscopy. ${ }^{21}$ Piezoelectric and electromagnetic are two main energy sources in extracorporeal lithotripsy aiming at fragmentation of stones. Prior fragmentation is necessary using an external lithotriptor or laser in cases of bigger calculi. Untoward effects can be reduced by continuous ultrasonographic monitoring. Requirement of multiple sessions and residual stone fragments inside the duct system are major limitations. Metallic dilators are treatment modality in case of stenoses. Balloon catheters under endoscopic control are preferred in case sialolith is peripherally localized. Surgical management may include salivary lithotripsy, basket retrieval and sialendoscopy. ${ }^{22}$ The patient in the present case presented with typical symptoms and the findings of clinical and radiographic examination were also typical. The diagnosis was made by clinical and radiographic examination and calculi retrieval by intraoral approach was selected as the treatment method due to the location of the stone. ${ }^{23}$ The presented case illustrates the necessity for proper diagnosis and importance of selecting the treatment of choice in cases of salivary gland disease. Postoperative follow-up is essential to ensure the patient is symptom free in the long-term.

\section{Conclusion}

Diagnosis of salivary calculi is mainly based on clinical symptoms and imaging. Management is by surgical means and has to be performed only after managing any infection or inflammation. Even though, surgical treatment is the mainstay treatment modality at present, minimally invasive techniques like lithotripsy will gain attention in the future.

\section{Source of funding}

None.

\section{Conflict of interest}

None.

\section{References}

1. Batori M, Mariotta G, Chatelou H, Casella G, Casella MC. Diagnostic and surgical management of submandibular gland sialolithiasis: Report of a stone of unusual size. Eur Rev Med Pharmacol Sci 2005;9:67-8.

2. Siddiqui SJ. Sialolithiasis: An unusually large submandibular salivary stone. Br Dent J 2002;193:89-91.

3. Nahlieli O, Eliav E, Hasson O, Zagury A, Baruchin AM. Pediatric sialolithiasis. Oral Surg Oral Med Oral Pathol Oral Radiol Endod 2000;90:709-12.

4. Bodner L. Giant salivary gland calculi: Diagnostic imaging and surgical management. Oral Surg Oral Med Oral Pathol Oral Radiol Endod 2002;94:320-3.

5. Kaban LB, Mulliken JB, Murray JE. Sialadenitis in childhood. Am J Surg 1978;135:570-6.

6. Marchal F, Kurt AM, Dulguerov P, Lehmann W. Retrograde theory in sialolithiasis formation. Arch Otolaryngol Head Neck Surg 2001;127:66-8.

7. Jager L, Menauer F, Holzknecht N. Sialolithiasis: MR Sialography of the Submandibular duct--An Alternative to Conventional Sialography and US? Radiol 2000;16(3):665-71.

8. Alyas F, Lewis K, Williams M, Moody AB, Wong KT, Ahuja AT, Howlett DC. Diseases of the Submandibular gland as demonstrated using high resolution ultrasound. Br J Radiol 2005;78(3):362-9.

9. Rudack C, Jorg S, Kloska S, Stoll W, Thiede O. Neither MRI, CT nor US is superior to diagnose tumours in the salivary glands- an extended case study. Head Face Med 2007;3(19):18 .

10. Klutmann S, Bohuslavizki KH, Kroger S, Bleckman C. Quantitative salivary gland scintigraphy. J Nucl Med Technol 1999;27(1):20-6.

11. Nahlieli O, Nakar LH, Nazarian Y, Turner MD. Sialoendoscopy: A new approach to salivary gland obstructive pathology. J Am Med Assoc 2006;137(10):1394-1400.

12. Gadodia A, Seith A, Sharma R, Thakar A, Parshad R. Magnetic resonance sialography using CISS and HASTE sequences in inflammatory salivary gland diseases: Comparison with digital sialography. Acta Radio 2010;51(2):156-63.

13. Isacsson G, Isberg A, Haverling M, Lundquist PG. Salivary calculi and chronic sialoadenitis of the submandibular gland: A radiographic and histologic study. Oral Surg Oral Med Oral Pathol 1984;58:622-7.

14. Oteri G, Procopio RM, Cicciù M. Giant salivary gland calculi (GSGC): Report of two cases. Open Dent J 2011;5:90-5.

15. Lustmann J, Regev E and Melamed Y: Sialolithiasis. A survey on 245 patients and a review of the literature. Int J Oral Maxillofac Surg 1990;19:135-8.

16. Andretta M, Tregnaghi A, Prosenikliev V, Staffieri A. Current opinions in sialolithiasis diagnosis and treatment. Acta Otorhinolaryngol Ital 2005;25:145-9.

17. Grases F, Santiago C, Simonet BM and Costa-Bauzá A: Sialolithiasis: mechanism of calculi formation and etiologic factors. Clin Chim Acta 2003;334:131-6.

18. Levy DM, Remine WH, Devine KD. Salivary gland calculi. Pain, swelling associated with eating. JAMA 1962;181:1115-9. 
19. Anneroth G, Eneroth CM and Isacsson G: Morphology of salivary calculi. The distribution of the inorganic component. $J$ Oral Pathol 1975;4:257-65.

20. Zenk J, Koch M, Klintworth N, König B, Konz K, Gillespie $\mathrm{MB}$, et al. Sialendoscopy in the diagnosis and treatment of sialolithiasis: a study on more than 1000 patients. Otolaryngol Head Neck Surg 2012;147:858-63.

21. Wilson KF, Meier JD, Ward PD. Salivary gland disorders. Am Fam Physician 2014;89:882-8.

22. Marchal F, Dulguerov P. Sialolithiasis Management: state of the art. Arch Otolaryngol Head Neck Surg 2003;129 (9):951-6.

23. Weissman JL. Imaging of the Salivary Glands. Semin Ultrasound CT MRI 1995;16(6):546-68.

How to cite the article: Wadhawan R, Mohan V, Gupta S, Lau H. Sialolithiasis in a 19 year old male: A case report. J Dent Specialities 2019;7(2):118-21. 